\title{
Proton beam therapy for ameloblastic carcinoma of the maxilla: report of a rare case
}

Kenji Yamagata $^{1}$, DDS, PhD, Hitoshi Ishikawa ${ }^{2}, \mathrm{MD}, \mathrm{PhD}$, Takashi Saito ${ }^{3}, \mathrm{MD}$, Hiroki Bukawa ${ }^{4} \mathrm{MD}$, DDS, PhD

${ }^{1}$ Assistant Professor, Department of Oral and Maxillofacial Surgery, Institute of Clinical medicine, Faculty of medicine, University of Tsukuba

2 Professor, Department of Radiation Oncology, Institute of Clinical medicine, Faculty of medicine, University of Tsukuba

${ }^{3}$ Resident, Department of Radiation Oncology, Institute of Clinical medicine, Faculty of medicine, University of Tsukuba

${ }^{4}$ Professor, Department of Oral and Maxillofacial Surgery, Institute of Clinical medicine, Faculty of medicine, University of Tsukuba

Correspondence: Kenji Yamagata, Department of Oral and Maxillofacial Surgery, Institute of Clinical medicine, Faculty of medicine, University of Tsukuba, 1-1-1 Tenodai, Tsukuba, Ibaraki 305-8575, Japan

y-kenji@md.tsukauba.ac.jp 


\begin{abstract}
Ameloblastic carcinoma (AC) is a rare malignant odontogenic tumor that combines the histological features of ameloblastoma with cytological atypia. The standard treatment for this lesion is wide local excision. Proton beam therapy (PBT), which can deliver high irradiation doses to target while avoiding irradiation to surrounding normal tissues but no reports of PBT for AC have been published so far. We here report a case of a 70-year-old Japanese woman with a pathological diagnosis of maxillary AC who refused surgical resection, and received hypofractionated PBT at a total dose of 69 Gy in 23 fractions. She is still alive for more than 5 years after PBT without any evidences of recurrence and side effects. This is the first successful treatment case after curative radiation therapy for maxillary AC.
\end{abstract}

Key words: Ameloblastic carcinoma (AC), Maxilla, Proton beam therapy (PBT) 


\section{Introduction}

Ameloblastic carcinoma (AC) is a rare malignant odontogenic tumor, with fewer than 200 reported cases. ${ }^{1}$ AC combines the histological features of ameloblastoma with cytological atypia regardless of whether it has metastasized. The standard treatment for the disease is wide local excision with cervical lymphnode dissection, but efficacy of radiotherapy (RT) or chemotherapy seems to be limited. ${ }^{2}$ There are a few case reports treated with RT using gamma-ray, X-ray, and carbon-ions, ${ }^{3-6}$ but there are no reports of proton beam therapy (PBT) for AC. The main role of $\mathrm{RT}$ is an adjuvant or salvage treatment after surgery. Patients treated with conventional external beam radiation have been reported to have long term control more than 10 years out with relatively few side effects. Here we firstly report a successful treatment by PBT for a case with AC of the maxilla.

\section{Case Report}

A 70-year-old Japanese woman was referred to our department in 2012. She had complained of a tumor at her left maxillary gingiva 2 months before. Uterine fibroids and goiter were recorded as her medical history Examination of the oral cavity revealed a soft elastic mass measuring approximately $20 \times 15 \mathrm{~mm}$ adjacent to the left molar region of the maxilla (Fig 1), but she did not complained of trismus. T2- weighted magnetic resonance images (MRI) showed a 43 × 22 x $21 \mathrm{~mm}$ high intensity tumor which was located at the posterior of the maxillary sinus and extended to the pterygomaxillary fossa. There was no cervical lymph-node 
metastasis. (Fig 2). A biopsy from the maxillary gingiva under local anesthesia was performed and histopathologically, basal-cell-like tumor-cell growth, irregular nests, and peripheral tumor-cell nests with penetrating palisades were observed. Inside the nest, the tumor-cell density was low, and the tumor cells exhibited pleomorphism and a stellate reticulum-like structure. The mitotic figures differed in size and had moderate to severe nuclear atypia. Nuclear mitosis was frequently observed $(>10 / 10$ HPF). Based on these histopathological findings, her tumor was confirmed as AC finally (Fig 3).

Cancer board recommended curative surgical resection of her tumor, but she refused to receive it and wanted to receive definitive $\mathrm{RT}$ as an alternative treatment. Radiation oncologists explained both characteristics of photon RT and PBT, and she selected PBT for the treatment. Hypofractionated PBT at a total PBT dose of 69 Gy in 23 fractions with a fractional dose of 3 Gy over 5 weeks, equivalent to 74.5 Gy with a conventional fraction dose of 2 Gy when using the linearquadratic model $(\alpha / \beta=10)$, was perfomed. PBT was planned using a threedimensional planning system based on CT images with a 5-mm slice thickness. The patient was immobilized in a supine position, under a thermoplastic mask. The initial clinical target volume (CVT) included a visible tumor with $10 \mathrm{~mm}$ margins for all directions and left maxillary sinus, but PBT fields were shrunken three times step by step (Fig 4).

Treatment was uneventful except for grade 2 dermatitis and stomatitis that occurred with 40 Gy. Five years after PBT, the patient is still alive with neither any 
recurrence nor any side effects. MRIs depict a slight hypertrophy of the sinus mucosa that has unchanged for five years since PBT (Fig 5). She continues to receive followed up examinations.

\section{Discussion}

AC was systematically reviewed by Saluja et al. (153 cases). ${ }^{1}$ The 2005 World Health Organization (WHO) classification divides AC into primary type; secondary type, intraosseous; and secondary type, peripheral. Most AC appears to arise de novo, but a few cases were reported to arise from preexisting ameloblastoma. Although our case was consistent with primary type AC, this subclassification may be unnecessarily complex for an already rare lesion, and the 2017 WHO classification lists a single diagnostic entity of AC but acknowledges varied histological features. ${ }^{7}$ $\mathrm{AC}$ has different clinical features in the maxilla and in the mandible, and has a lower incidence in the maxilla than in the mandible. ${ }^{8}$ Maxillary AC lesions appear to occur slightly later in life (average age 56.7 years) than in the mandible. ${ }^{9}$ Although AC lesions tend toward aggressive local growth and local relapse, distant metastases are uncommon. ${ }^{10}$ In our case, the patient was older than the average age in previously reported cases, and the AC did not exhibit aggressive growth and relapse, fortunately.

When AC arises de novo, diagnosis can be difficult because it must be differentiated from primary intraosseous squamous cell carcinoma, metastatic carcinoma of the jaw, and central high-grade mucoepidermoid carcinoma. Therefore, 
findings of typical histological features of ameloblastoma, such as peripheral palisading, reverse polarity, and a stellate reticulum-like structure, provide clues to a diagnosis of AC. ${ }^{11}$ Although our case arose de novo, the diagnosis was not particularly difficult because of the peripheral palisading, stellate reticulum-like structure, and frequent nuclear mitosis observed.

The most favorable treatment for $\mathrm{AC}$ is thought to be early surgical management with or without RT or chemotherapy, determined by the site and extent of the tumor, ${ }^{1}$ because it produced the highest mean survival time (140 months, $95 \%$ CI 106-174), compared to RT (17.5 months, 95\% CI 2.95-32.1) and chemotherapy (8 months, $95 \%$ CI 8-8). ${ }^{1}$ The main role of $\mathrm{RT}$ is an adjuvant or salvage treatment after surgery, ${ }^{2}$ patients treated with postoperative conventional RT who have a longterm local control more than 10 years with relative few late sequelae. ${ }^{12}$ On the other hand, outcomes of non-conventional RT for each two cases with recurrences or residual tumors after surgery were reported as case presentations (Table 1). Jensen et al. reported a successful case with recurrent AC treated with carbon-ion therapy for recurrent AC, but a follow-up period was very short (3 months). ${ }^{4}$ Perera et al. reported the use of gamma-knife stereotactic radiosurgery for $\mathrm{AC},{ }^{3}$ with a survival of 2.5 years from treatment without disease at the treated site. Helical tomotherapy, a unique intensity-modulated radiotherapy delivery system, was performed for two cases of $\mathrm{AC}$ for the postoperative treatment of residual tumors. ${ }^{5,6}$ The four cases were treated with miscellaneous dose fractionation schedules at different total doses ranging from 16 to $60 \mathrm{~Gy}$, and followed for 3 to 30 months. In our case, a prescribed 
PBT dose was initially set at 60 Gy in 20 fractions, but the a visible tumor remained on CT images at time after 51 Gy. Therefore, we decided to add a boost PBT of 9 Gy in 3 fractions using shrunken fields covering only tumors without any margins (Fig 4). This is the first report showing a successful case treated with definitive RT as initial treatment, and she has been followed up for the longest period (more than 5 years) without any recurrences. Furthermore, no severe acute or late complications were observed, fortunately. The result suggests that PBT has a possibility to manage AC patients who are regarded as not only medically inoperable but also suitable for curative surgery. Further experience may show the efficacy of PBT for AC patients in the future. 


\section{References}

1. Saluja TS, Hosalkar R: Reconnoitre ameloblastic carcinoma: A prognostic update. Oral Oncol 77:118, 2018

2. Benlyazid A, Lacroix-Triki M, Aziza R et al.: Ameloblastic carcinoma of the maxilla: case report and review of the literature. Oral Surg Oral Med Oral Pathol Oral Radiol Endod 104:e17, 2007

3. Perera E, Lindquist C, Hughes C, Thomas S: The use of Gamma Knife stereotactic radiosurgery in the treatment of ameloblastic carcinoma. Int J Oral Maxillofac Surg 42:934, 2013

4. Jensen AD, Ecker S, Ellerbrock M et al.: Carbon ion therapy for ameloblastic carcinoma. Radiat Oncol 6:13, 2011

5. Takahashi Y, Bandoh N, Miyamoto A, Kamada H: Single-Fraction Helical Tomotherapy for Ameloblastic Carcinoma. J Oral Maxillofac Surg $74: 302,2016$

6. Koca T, Basaran H, Arslan D et al.: Prominent response with helical tomotherapy in recurrent ameloblastic carcinoma of maxillary sinus: a case report. Radiat Oncol 9:157, 2014

7. Speight PM, Takata T: New tumour entities in the 4th edition of the World Health Organization Classification of Head and Neck tumours: odontogenic and maxillofacial bone tumours. Virchows Arch, 2017

8. Kruse AL, Zwahlen RA, Gratz KW: New classification of maxillary ameloblastic carcinoma based on an evidence-based literature review over the last 60 years. Head Neck Oncol 1:31, 2009

9. Dhir K, Sciubba J, Tufano RP: Ameloblastic carcinoma of the maxilla. Oral Oncol 39:736, 2003

10. Avon SL, McComb J, Clokie C: Ameloblastic carcinoma: case report and literature review. J Can Dent Assoc 69:573, 2003

11. Yoon HJ, Hong SP, Lee JI et al.: Ameloblastic carcinoma: an analysis of 6 cases with review of the literature. Oral Surg Oral Med Oral Pathol Oral Radiol Endod 108:904, 2009

12. Kennedy WR, Werning JW, Kaye FJ, Mendenhall WM: Treatment of ameloblastoma and ameloblastic carcinoma with radiotherapy. Eur Arch 
Otorhinolaryngol 273:3293, 2016

FIGURE 1. Examination of the oral cavity

Intraoral examination revealed a soft elastic mass measuring approximately $20 \mathrm{x}$ $15 \mathrm{~mm}$ in the posterior left molar of the maxilla.

FIGURE 2. MRI findings

(A) Axial T2-weighted (T2WI) and (B) coronal STIR scans, depicting a $43 \times 22 \times 21$ $\mathrm{mm}$ mass with high signal intensity. The mass was located at the posterior of the maxillary sinus and extended to the pterygomaxillary fossa. 
Figure 3. Pathological findings

HE-stained tissue at (A) low and (B) high power magnification. The basal cell-like tumor-cell growth showed irregular nests and peripheral tumor cells of penetrating palisade nests. A follicular-growth pattern was observed with stellate reticulumlike tumor cells. The mitotic figures were different in size and showed moderate to severe nuclear atypia, with frequent nuclear mitosis (>10/10 HPF).

FIGURE 4. Proton-beam therapy dose distribution of $69 \mathrm{~Gy} / 23 \mathrm{Fr}$ (equivalent dose:

\subsection{Gy)}

(A1) Initial treatment plan (Axial), (A2)Initial treatment plan (Lateral)

(B1) Final (4th) treatment plan(Axial), (B2)Final (4th) treatment plan(Lateral)

Figure 5. Follow-up MRI 5 years after proton therapy

(A) Axial T2WI and (B) coronal STIR MR images showed a slight hypertrophy of the sinus mucosa, which did not change during the 5-year follow-up period.

Table. 1 Reported non-conventional RT treatments for AC 
Fig. 1

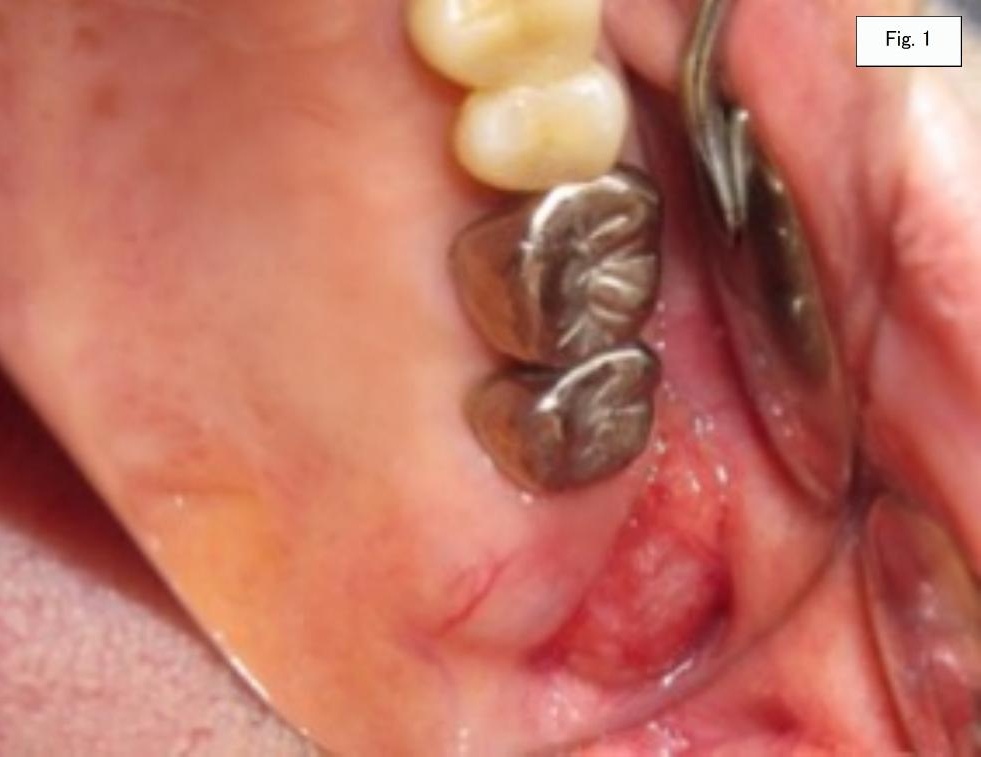




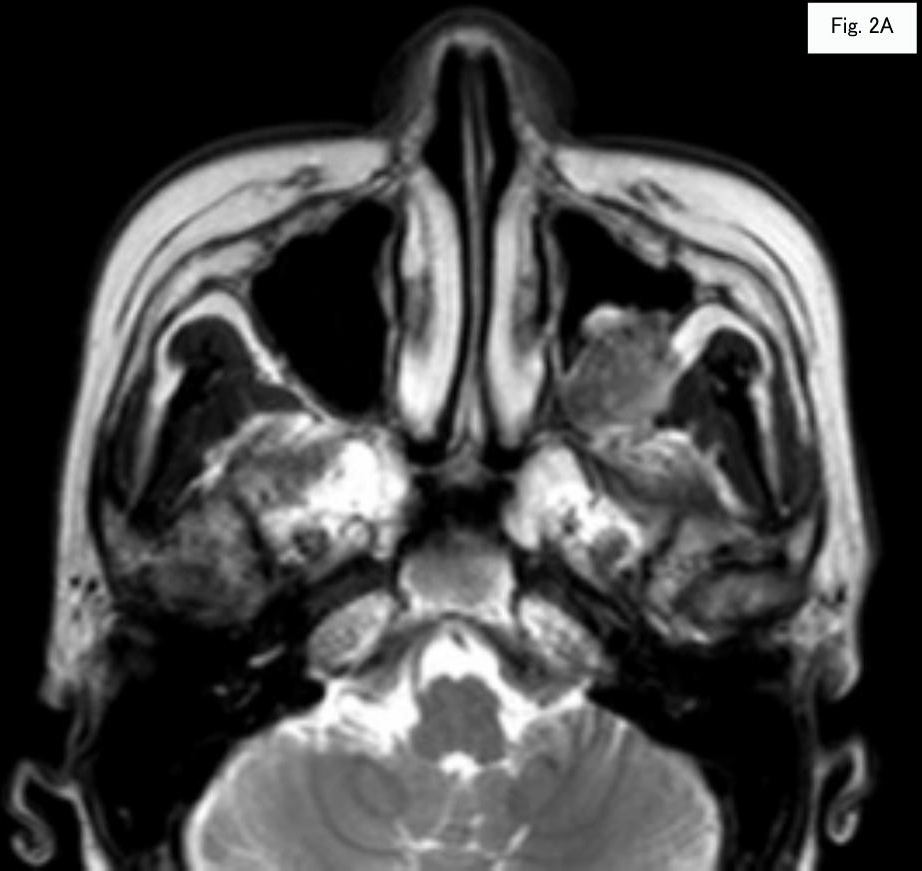





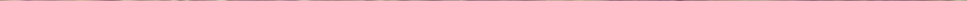


Fig. 3B

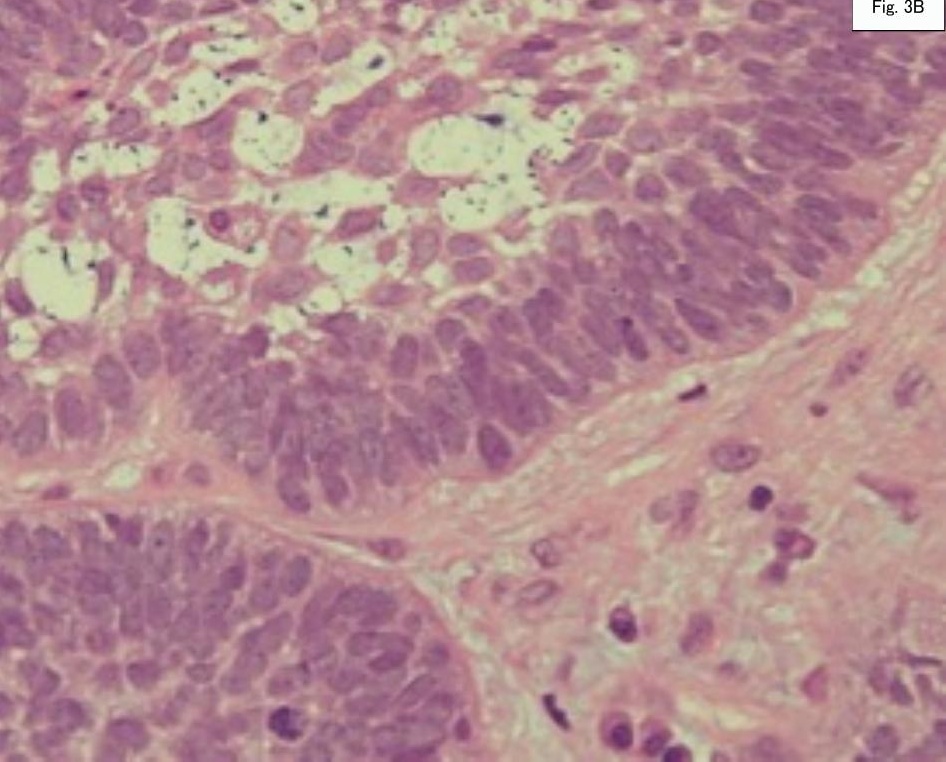


Fig. 4A1 
Fig. $4 A 2$

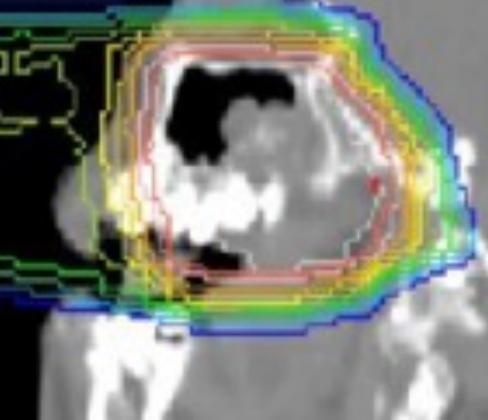


Fig. 4B1 
Fig. 4B2 
Fig. $5 \mathrm{~A}$

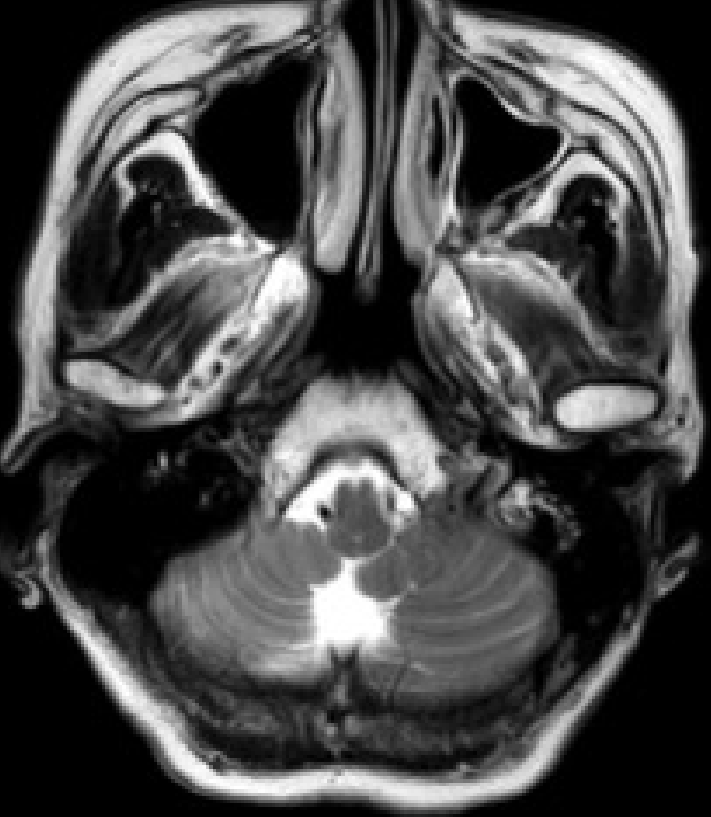




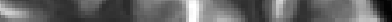


TABLE 1. Reported non-conventional RT treatments for AC

\begin{tabular}{|c|c|c|c|c|c|c|}
\hline No & $\begin{array}{l}\text { Author } \\
\text { (year) }\end{array}$ & Patient & Treatment & Dose & Prognosis & Duration \\
\hline 1 & $\begin{array}{l}\text { Jensen et } \\
\text { al. (2011) }\end{array}$ & 71/M & $\begin{array}{l}\text { Carbon ion } \\
\text { therapy }\end{array}$ & $60 \mathrm{GyE} / 20 \mathrm{fr}$ & Alive & 3 months \\
\hline 2 & $\begin{array}{l}\text { Perera et al. } \\
\text { (2013) }\end{array}$ & $35 / \mathrm{M}$ & $\begin{array}{l}\text { Gamma knife } \\
\text { stereotactic } \\
\text { radiosurgery }\end{array}$ & 16Gy/1fr & $\begin{array}{l}\text { Death } \\
\text { from } \\
\text { cancer }\end{array}$ & 2.5 years \\
\hline 3 & $\begin{array}{l}\text { Koca et al. } \\
(2014)\end{array}$ & $35 / \mathrm{M}$ & $\begin{array}{l}\text { Helical } \\
\text { tomotherapy }\end{array}$ & 60Gy & Alive & 1 year \\
\hline 4 & $\begin{array}{l}\text { Takahashi } \\
\text { et al. (2016) }\end{array}$ & $58 / \mathrm{M}$ & $\begin{array}{l}\text { Helical } \\
\text { tomotherapy }\end{array}$ & $25 \mathrm{~Gy} / 1 \mathrm{fr}$ & Alive & 19months \\
\hline 5 & $\begin{array}{l}\text { Our case } \\
(2018)\end{array}$ & $70 / \mathrm{F}$ & $\begin{array}{l}\text { Proton } \\
\text { therapy }\end{array}$ & $69 \mathrm{~Gy} / 23 \mathrm{fr}$ & Alive & 5 years \\
\hline
\end{tabular}

